Vol. 4, No. 1 | January - June 2020

\title{
Awareness regarding Coronavirus pandemic among the population of Sindh, Pakistan: A cross-sectional study
}

\author{
Khalida Shaikh ${ }^{1}$, Areeba Memon², Irfan Ahmed Memon ${ }^{3}$, Zulfiqar Ali \\ Laghari $^{4}$ Abdul Moiz memon ${ }^{5}$
}

\begin{abstract}
:
Methods: This is a cross-sectional descriptive study and was carried out in Sindh, Pakistan. 588 people from different cities of Sindh were asked to fill a questionnaire that tested their attitudes, knowledge, and practices related to the SARS-CoV-2 pandemic. Results: Television and other social media platforms have led to increased dissemination of knowledge among the population. Their increased understanding has led them to be more compliant with adopting precautionary measures, as frequent handwashing was seen in $89.8 \%$ and social distancing in $87.2 \%$. The results also showed a greater prevalence of myths among the population. Conclusion: Increased access to correct knowledge can help to dissipate misconceptions and help spread accurate knowledge about the role that the public should play in reducing disease transmission.
\end{abstract}

Keywords: SARS-CoV-2; Pandemic; COVID-19; Awareness; Severe acute respiratory syndrome coronavirus-2.

\section{Introduction}

The appearance of severe acute respiratory syndrome coronavirus 2 (SARS-CoV-2) triggered a severe global pandemic and is a major public health issue [1]. It came in realization in December 2019 in Wuhan, China, when a group of patients was verified to have novel coronavirus infection. Politically and geographically Pakistan and China are closely connected. Several Chinese people are working on multiple developmental projects in Pakistan, Pakistan took strong measures such as closing its border with China, scrutinizing flights from China and arranging for its workforce and students in affected cities to remain there so that potential spread could be avoided. But the situation got out of control when the virus spread in Iran, many Pakistanis are involved in Iran for work and regularly visit the country for religious purposes. For many reasons, a controlled exit from Iran was not possible also Iranians asked other countries to call back

${ }^{1}$ Department of Physiology, Liaquat University of Medical \& Health Sciences, Pakistan.

${ }^{2}$ Aga Khan University Hospital, Karachi, Pakistan.

${ }^{3}$ Department of City and Regional Planning, Mehran University of Engineering \& Technology, Jamshoro, Pakistan.

${ }^{4}$ Department of Physiology Sindh University, Jamshoro, Pakistan

${ }^{5}$ Mechanical Engineering Department, Mehran University of Engineering \& Technology, Jamshoro, Pakistan

Corresponding Author: khalidashaikh1@gmail.com SJCMS | E-ISSN: 2520-0755 | Vol. 4 | No. 1 | $\odot 2020$ Sukkur IBA University 
Khalida Shaikh (et al.), Awareness regarding Coronavirus pandemic among the population of Sindh, Pakistan: A crosssectional study

(pp. $28-36)$

their nationals. All these factors led to an evident spread of this outbreak into Pakistan affecting many people. According to COVID 19 visualizer, the number of total cases reported globally as of $10^{\text {th }}$ July 2020 was $12,434,830$ with 558,416 deaths out of which 243,599 were reported in Pakistan with 5,058 deceased and 149,092 recovered. The number of cases keeps increasing daily causing a huge problem.

According to current evidence, the COVID-19 virus is primarily transmitted between people through respiratory droplets and contact routes [2]. The mean COVID-19 incubation time was a little different in recent publications. Wang et al, reported 5 days, 7 days, and 8 days for median durations from first signs to dyspnea, hospital admission, and acute respiratory distress syndrome (ARDS) respectively in 138 cases [3]. The mean incubation period of this infection was estimated to be 4.6 days and $95 \%$ of disease onset happened within ten days [4]. The symptoms occurring in the disease are nonspecific and range from being asymptomatic to the development of severe pneumonia and even death with fever, cough, myalgia, and fatigue being the most common ones [5-7].

As of now, there's no approved antiviral treatment or vaccine present for this disease.[8] Thus, proper management of such patients and strict practice of precautions by the general public is critical in saving the lives of people affected and stopping the transmission of the disease to those unaffected by it respectively. The government along with global public health bodies is trying hard to increase the awareness regarding the disease, it's the transmission and precautionary methods amongst the general public to stop the transmission of this communicable disease [9].

Public health and infection prevention initiatives are desperately required to reduce the damage associated with COVID-19 and minimize the global dissemination of the virus.[10] But, Due to limited data being available on how to increase public awareness and what methods are effective there is a lack of evidence to devise appropriate strategies to increase the public's awareness. Due to inappropriate usage of technology, false information is being circulated around and as a result, people with limited knowledge are adapting practices that might prove dangerous. This research aims at providing an idea of how aware the people in Pakistan about safe precautionary practices are and help the policymakers in making an effective plan towards spreading the right knowledge regarding this global pandemic.

\section{Materials and Methods}

This is a cross-sectional, descriptive study carried out in Sindh, Pakistan. The study lasted three months (i.e.) January to April 2020. 588 participants were included in the study. All the chosen subjects had a secondary or higher level of education and were aged $\geq$ 20 years.

For data collection, a detailed Questionnaire was prepared, and the pilot tested amongst 10 participants to determine the clarity and acceptability of the questions. These responses were not included in the final study. The final questionnaire was distributed amongst the selected group of volunteers. The volunteers were each assigned a city and they approached every participant individually to ensure standardized filling of the questionnaire. Written consent was also obtained from all participants.

The questionnaire was designed in English and included some well-known myths that were taken from WHO's site and restructured to see if people respond with true or false for each statement. Further, it inquired about precautionary measures being taken during this pandemic and their city of residence. Each participant's satisfaction level regarding the steps being taken by the government to handle the current health crisis and their stress level related to the lockdown being practiced was also included in the questionnaire. The 
Khalida Shaikh (et al.), Awareness regarding Coronavirus pandemic among the population of Sindh, Pakistan: A crosssectional study (pp. $28-36)$

questions from the Perceived Stress Scale (PSS) were asked to determine whether the participant was stressed or not.

All the responses collected were then divided into three categories based on the city of residence and its population. If the city of residence had a population of $\geq 0.7$ million it was marked as category 1(large cities). If the city population was $<0.7$ and $\geq 0.3$ million, it was marked as belonging to category 2 (medium cities). And a population of $<0.3$ million belonged to category 3(smaller towns).

The data collected, was then transferred to an Excel sheet and further coded and analyzed using IBM SPSS version 23.0. Chi-Square test was used to compare categorical groups and check whether a difference exists between categories. The data was presented using Frequencies and Proportions via Tables and Bar graphs.

\section{Results}

The results showed that people in all the cities got informed about the latest knowledge on COVID via multiple sources. It shows that nose, and mouth (49.2\%) along with disinfecting shared surfaces such as doorknobs and table-tops, etc. (47.2\%). (Figure 2).

Figure 3 shows whether the participants practicing social distancing find it to be stressful or not. Most people in medium television and social media remain the major source of information overall. In larger cities, 390 people out of $474(82.27 \%)$ had social media as one of their sources of information thus catering the majority with television being the second major source $(71.5 \%)$. In medium cities, 30 out of 42 people $(71.4 \%)$ had access to the information being shown on television and 27 out of $30(64.2 \%)$ people got their information via social media. In smaller towns, the responses were quite variable with television being the major source of information (62.5\%). Government/NGO volunteers contributed the least in all the cities. Moreover, in smaller cities contribution via websites/blogs were also quite low. (Figure 1)

The most frequently observed precautionary measure amongst the study population was regular handwashing $(89.8 \%)$. Moreover, many participants $(82.7 \%)$ practiced social distancing. In addition to that, most participants reported avoiding shaking hands $(78.7 \%)$ and taking precautionary measures in public (69\%). Participants also avoided touching, eyes,

$(64.3 \%)$ and smaller cities (58.3\%) didn't find social distancing to be stressful. Although, the number of those finding social distancing to be stressful is significant enough and cannot be ignored. In larger cities, however, 243 out of 474 people $(51.2 \%)$ found social distancing to be stressful. 
Khalida Shaikh (et al.), Awareness regarding Coronavirus pandemic among the population of Sindh, Pakistan: A crosssectional study

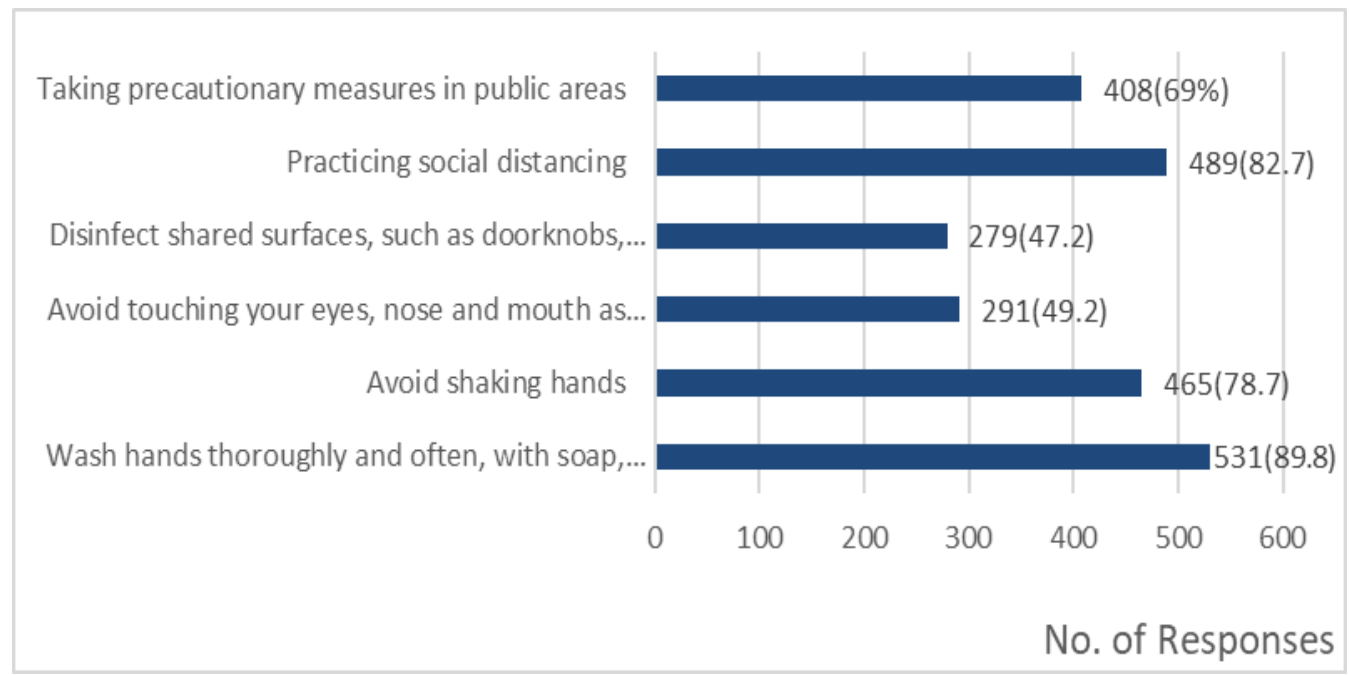

Fig 1. source of information in small, medium and large cities

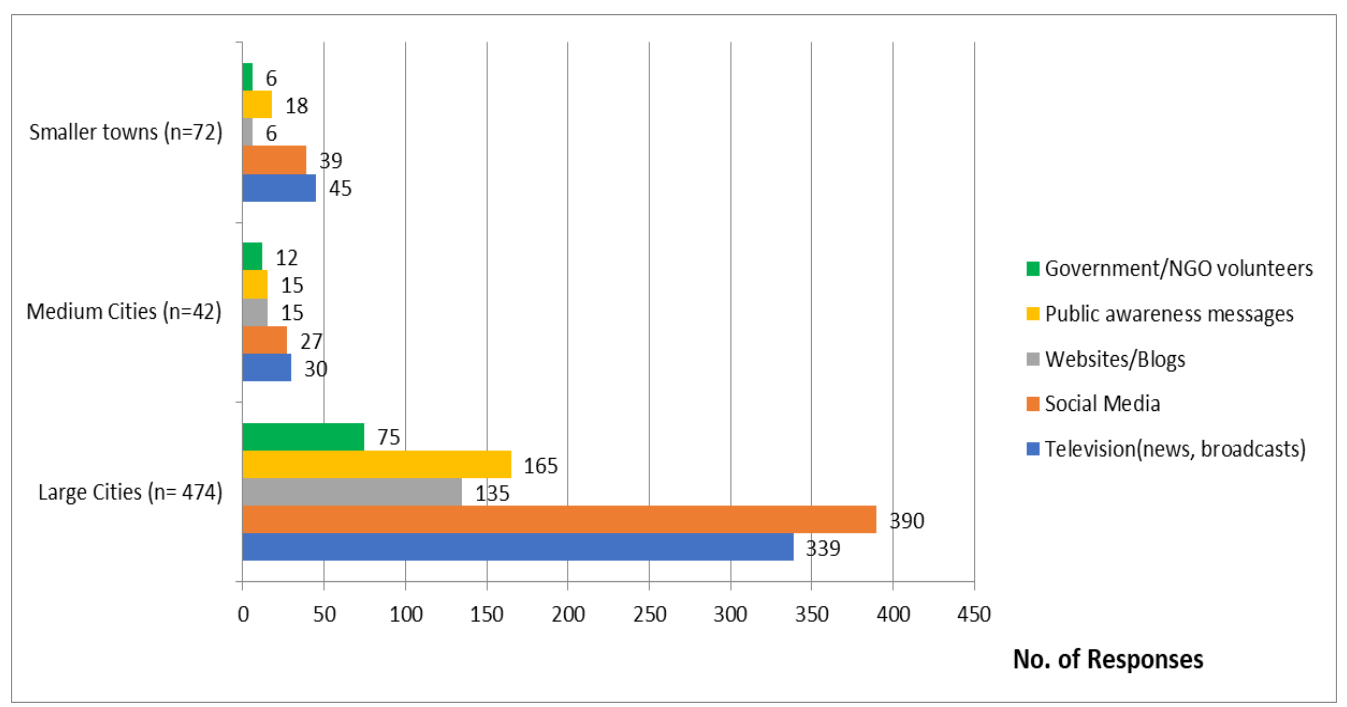

Fig 2. Percentage of $(\%)$ of precautionary measures being taken against SARS-COV-2 


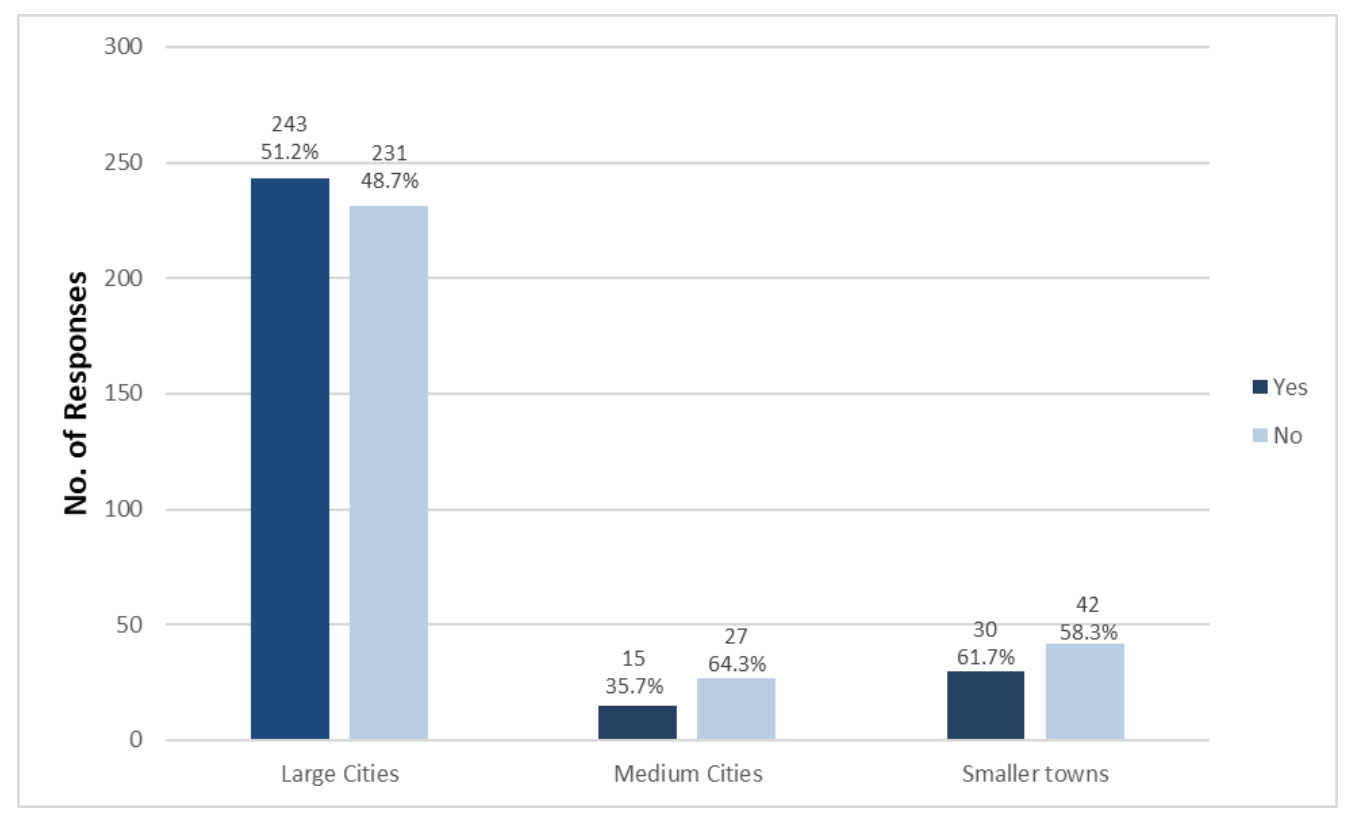

Fig 3. Bar-Graph showing whether people find social distancing stressful (Yes) or not (No)

Table 1 shows many people believe in myths related to COVID 19, which can result in wrong precautions and prevention procedures. Spraying alcohol or chlorine all over your body will not kill viruses was the most common myth among the study population as the largest number of people responded to this question wrongly, followed by thermal scanners that can detect infected people.

The high Chi-square values for two of the myths i.e. "The new coronavirus CANNOT be transmitted through mosquito bites" $\left(\mathrm{X}^{2}=12.688, \mathrm{P}<0.01\right)$ and "Thermal scanners CAN detect people who are infected" $\left(\mathrm{X}^{2}=6.672, \mathrm{P}<0.05\right)$ suggest that there is a significant association between them and division of cities that are statistically significant. For other myths, the situation is more serious as these exist indifferent to any category and are existent in a larger number of people.

\section{Discussion}

This study revealed that the ongoing pandemic has increased the stress levels amongst the population. There were several studies conducted in the past, assessing the awareness, knowledge, and practices about such infectious disease outbreaks that took place in the past [11]. But the literature search has not found any such study regarding this recent outbreak of SARS-CoV-2. Therefore, the study can provide data to the public health policymakers necessary to devise effective prevention strategies. This research showed that the majority of people are aware of the coronavirus situation.

The participants got their basic necessary information via television and social media, as they remain the top two sources for every category. This was expected as in a developing country like Pakistan, where television and smartphones are a cheap source of entertainment and thus a common source of 
Khalida Shaikh (et al.), Awareness regarding Coronavirus pandemic among the population of Sindh, Pakistan: A crosssectional study

(pp. $28-36)$

acquiring knowledge and information. The government/NGO awareness campaigns and pandemic situation and subsequent increase in the number of deaths have resulted in a limited number of people volunteering in thus their contribution remains the lowest amongst each category.

Table 1. Knowledge about SARS-COV-2 amongst participants of small, medium and large cities

\begin{tabular}{|c|c|c|c|c|c|}
\hline Myths & $\begin{array}{c}\text { Category } \\
1 \\
\text { Large } \\
\text { Cities } \\
\mathrm{n}(\%) \\
\end{array}$ & $\begin{array}{c}\text { Category } \\
2 \\
\text { Medium } \\
\text { Cities } \\
\mathrm{n}(\%) \\
\end{array}$ & $\begin{array}{l}\text { Category } 3 \\
\text { Smaller } \\
\text { Towns } \\
\mathrm{n}(\%)\end{array}$ & $\mathrm{X}^{2}$ & $\begin{array}{c}\mathrm{P}- \\
\text { value }\end{array}$ \\
\hline $\begin{array}{c}\text { COVID-19 virus can ONLY be } \\
\text { transmitted in areas with cold and dry } \\
\text { climates. (True) } \\
\text { (False) }\end{array}$ & $\begin{array}{l}108(22.8) \\
366(77.2)\end{array}$ & $\begin{array}{c}9(21.4) \\
33(78.6)\end{array}$ & $\begin{array}{l}21(29.2) \\
51(70.8)\end{array}$ & 0.507 & 0.776 \\
\hline $\begin{array}{c}\text { The new coronavirus CANNOT be } \\
\text { transmitted through mosquito bites. } \\
\text { (False) } \\
\text { (True) }\end{array}$ & $\begin{array}{c}63(13.3) \\
411(86.7)\end{array}$ & $\begin{array}{l}21(50) \\
21(50)\end{array}$ & $\begin{array}{l}12(16.7) \\
60(83.3)\end{array}$ & 12.688 & 0.002 \\
\hline $\begin{array}{l}\text { Hand dryers ARE effective in killing the } \\
\text { new coronavirus. (True) } \\
\text { (False) }\end{array}$ & $\begin{array}{c}99(20.9) \\
375(79.1) \\
\end{array}$ & $\begin{array}{c}9(21.4) \\
33(78.6) \\
\end{array}$ & $\begin{array}{l}15(20.8) \\
57(79.2)\end{array}$ & 0.002 & 0.999 \\
\hline $\begin{array}{c}\text { Ultraviolet disinfection lamp CAN kill } \\
\text { the new coronavirus. (True) } \\
\text { (False) }\end{array}$ & $\begin{array}{l}147(31) \\
327(69)\end{array}$ & $\begin{array}{l}12(28.6) \\
30(71.4)\end{array}$ & $\begin{array}{l}21(29.2) \\
51(70.8)\end{array}$ & 0.063 & 0.969 \\
\hline $\begin{array}{c}\text { Thermal scanners CAN detect infected } \\
\text { people. (True) } \\
\text { (False) }\end{array}$ & $\begin{array}{c}232 \\
(48.94) \\
242(50.6)\end{array}$ & $\begin{array}{l}21(50) \\
21(50)\end{array}$ & $\begin{array}{l}42(58.3) \\
30(41.7)\end{array}$ & 6.672 & 0.045 \\
\hline $\begin{array}{c}\text { Taking a hot bath does NOT prevent the } \\
\text { new coronavirus disease. (False) } \\
\text { (True) }\end{array}$ & $\begin{array}{l}189(39.9) \\
285(60.1)\end{array}$ & $\begin{array}{l}18(42.9) \\
24(57.1)\end{array}$ & $\begin{array}{l}33(45.8) \\
39(54.2)\end{array}$ & 1.756 & 0.416 \\
\hline $\begin{array}{c}\text { Spraying alcohol or chlorine all over } \\
\text { your body will NOT kill viruses. (False) } \\
\text { (True) }\end{array}$ & $\begin{array}{l}243(51.3) \\
231(48.7)\end{array}$ & $\begin{array}{l}27(64.3) \\
15(35.7)\end{array}$ & $\begin{array}{l}36(50) \\
36(50)\end{array}$ & 0.919 & 0.632 \\
\hline $\begin{array}{l}\text { Vaccines against pneumonia, such as } \\
\text { pneumococcal vaccine and } \\
\text { Haemophilus influenza type B (Hib) } \\
\text { vaccine, do NOT protect against the } \\
\text { new coronavirus. (False) } \\
\text { (True) }\end{array}$ & $\begin{array}{c}84(17.7) \\
390(82.3)\end{array}$ & $\begin{array}{c}9(21.4) \\
33(78.6)\end{array}$ & $\begin{array}{c}6(8.3) \\
66(91.7)\end{array}$ & 1.539 & 0.463 \\
\hline $\begin{array}{c}\text { Eating garlic CAN help prevent } \\
\text { infection with the new coronavirus. } \\
\text { (True) } \\
\text { (False) }\end{array}$ & $\begin{array}{l}108(22.8) \\
366(77.2)\end{array}$ & $\begin{array}{c}6(14.3) \\
36(85.7)\end{array}$ & $\begin{array}{l}27(37.5) \\
45(62.7)\end{array}$ & 3.252 & 0.197 \\
\hline $\begin{array}{c}\text { New coronavirus infects ONLY older } \\
\text { people or people with preexisting } \\
\text { medical conditions. (True) } \\
\text { (False) }\end{array}$ & $\begin{array}{c}57(12) \\
417(88)\end{array}$ & $\begin{array}{l}9(21.4) \\
33(78.6)\end{array}$ & $\begin{array}{l}12(16.7) \\
60(83.3)\end{array}$ & 1.263 & 0.532 \\
\hline $\begin{array}{c}\text { Antibiotics CAN be used as a means of } \\
\text { prevention or treatment. (True) } \\
\text { (False) }\end{array}$ & $\begin{array}{l}111(23.4) \\
363(76.6)\end{array}$ & $\begin{array}{l}15(35.7) \\
27(64.3)\end{array}$ & $\begin{array}{l}24(33.3) \\
48(66.7)\end{array}$ & 1.904 & 0.386 \\
\hline
\end{tabular}


Khalida Shaikh (et al.), Awareness regarding Coronavirus pandemic among the population of Sindh, Pakistan: A crosssectional study

Social distancing and frequent
handwashing are the most emphasized
behavioral interventions by health
professionals to reduce the risk of
transmission. [12] The results of the
population seem consistent with this as
handwashing (89.8\%) and social distancing
(82.7\%) are practiced the most. A significant
number of people practicing social distancing
find it stressful. The proportion of those in
larger cities was greater than those in medium
and smaller cities. Mostly, daily wage workers
work in major cities and are most affected by
lockdown, which has the primary goal of
social distancing, hence for them social
distancing is stressful and a difficult pill to
swallow [13, 14].

Many people find it to have negative effects on their health. While technology has helped people communicate with their friends and families, for the majority, the main part of their everyday experience is nonverbal contact, and being unable to do so triggers stress in many including those residing in medium and smaller cities. Most women and children in smaller cities are usually homebound and that may have contributed to lower figures than those in larger cities.

An important finding in this study is the high prevalence of myths amongst participants. We tested the knowledge of participants regarding the most commonly encountered misconceptions that are being circulated on different media platforms. These myths are addressed by WHO and all the information is available on their website. Despite that, at least $20 \%$ of participants in each category believe that this virus can only be transmitted in cold and dry climate although there is no indication that COVID-19 cases will decline as the weather gets warmer[15] or humid [16]. In middle cities, people were equally split as to whether mosquitoes act as a vector for this viral disease or not. Studies in the past have shown that it spreads from human to human transmission and that mosquitoes have no role in its

transmission [5, 17]. Moreover, ultraviolet disinfection lamps and hand dryers do not play any part in killing this new coronavirus (SARS-CoV-2) and the ultraviolet light can irritate the skin and is harmful [18]. A vast number of people believe that thermal scanners are used to identify people infected with the new coronavirus. The role of thermal scanners, however, is restricted to the diagnosis of the people with fever, which is one of the symptoms of this disease [19]. However other people can have the disease and yet go undetected as it takes 2 to 10 days before individuals get ill and develop a fever [20]. Alcohol and chlorine can be used to disinfect surfaces but they have no role in killing the viruses that have already entered the body and these chemicals can prove harmful to the body [21]. Supportive treatment is currently the only treatment option available for patients affected with SARS-CoV-2 virus and although several attempts to develop a vaccine have been made, the effectiveness of pneumococcal vaccines in protecting people against this disease has not yet been proven in any research [22, 23]. In addition to that, the study showed that many people believe antibiotics to be a cure for this disease. Antibiotics are to be used against bacterial infections and they have no role in preventing viral infections. Antibiotics are to be used only when appropriate and not as a treatment of viral infections as this can exacerbate the antibiotic resistance issue [24]. The prevalence of myths in this society shows that people also get the wrong information via some of these platforms and that can be risky because people continue to follow such beliefs and some of them can be detrimental and may cause new issues in these challenging times.

Therefore, this study demonstrates that awareness programs are actually effective in spreading knowledge, but attention must be paid to the attitudes of the local population and their perceptions should also be taken into account when planning such awareness campaigns. 
Khalida Shaikh (et al.), Awareness regarding Coronavirus pandemic among the population of Sindh, Pakistan: A crosssectional study

\section{Conclusion}

The knowledge regarding this pandemic isn't adequate as the misconceptions continue to exist among a significant percentage of the population. The data gathered in this study could be used to track public opinion and attitudes to develop new health policies and awareness-raising strategies. Increased access to correct knowledge can help to dissipate misconceptions and help spread accurate knowledge about the role that the public should play in reducing disease transmission

\section{REFERENCES}

[1] C.-C. Lai, T.-P. Shih, W.-C. Ko, H.-J. Tang, and P.-R. J. I. j. o. a. a. Hsueh, "Severe acute respiratory syndrome coronavirus 2 (SARSCoV-2) and coronavirus disease-2019 (COVID-19): the epidemic and the challenges," p. 105924, 2020.

[2] J. Liu et al., "Community Transmission of Severe Acute Respiratory Syndrome Coronavirus 2, Shenzhen, China, 2020," (in eng), Emerg Infect Dis, vol. 26, no. 6, Jun 17, 2020.

[3] D. Wang et al., "Clinical Characteristics of 138 Hospitalized Patients With 2019 Novel Coronavirus-Infected Pneumonia in Wuhan, China," JAMA, vol. 323, no. 11, pp. 10611069, 2020.

[4] C. A. Donnelly et al., "Epidemiological determinants of spread of causal agent of severe acute respiratory syndrome in Hong Kong," vol. 361, no. 9371, pp. 1761-1766, 2003.

[5] J. F.-W. Chan et al., "A familial cluster of pneumonia associated with the 2019 novel coronavirus indicating person-to-person transmission: a study of a family cluster," vol. 395, no. 10223, pp. 514-523, 2020.

[6] N. Chen et al., "Epidemiological and clinical characteristics of 99 cases of 2019 novel coronavirus pneumonia in Wuhan, China: a descriptive study," vol. 395, no. 10223, pp. 507-513, 2020.

[7] C. Huang et al., "Clinical features of patients infected with 2019 novel coronavirus in Wuhan, China," vol. 395, no. 10223, pp. 497506, 2020.
[8] L. I. D. J. T. L. I. d. The "Challenges of coronavirus disease 2019," vol. 20, no. 3, p. $261,2020$.

[9] A. Zumla, D. S. Hui, E. I. Azhar, Z. A. Memish, and M. J. T. L. Maeurer, "Reducing mortality from 2019-nCoV: host-directed therapies should be an option," vol. 395, no. 10224, pp. e35-e36, 2020.

[10] F. Song et al., "Emerging 2019 novel coronavirus (2019-nCoV) pneumonia," p. 200274, 2020.

[11] J. Shi et al., "Knowledge, attitudes, and practices of nonpharmaceutical interventions following school dismissals during the 2009 influenza A H1N1 pandemic in Michigan, United States," vol. 9, no. 4, 2014.

[12] T. Wise, T. D. Zbozinek, G. Michelini, and C. C. Hagan, "Changes in risk perception and protective behavior during the first week of the COVID-19 pandemic in the United States," 2020.

[13] U. W. Chohan, "Forecasting the Economic Impact of Coronavirus on Developing Countries: Case of Pakistan," 2020.

[14] B. Krishnakumar, S. J. J. o. M. Rana, Immunology, and Infection, "COVID 19 in INDIA: Strategies to combat from combination threat of life and livelihood," 2020.

[15] Y. Zhu and J. J. S. o. T. T. E. Xie, "Association between ambient temperature and COVID-19 infection in 122 cities from China," p. 138201, 2020.

[16] P. Shi et al., "The impact of temperature and absolute humidity on the coronavirus disease 2019 (COVID-19) outbreak-evidence from China," 2020.

[17] Q. Li et al., "Early transmission dynamics in Wuhan, China, of novel coronavirus-infected pneumonia," 2020.

[18] W. H. Organization. Coronavirus disease (COVID-19) advice for the public: Myth busters. Available: https://www.who.int/emergencies/diseases/no vel-coronavirus-2019/advice-forpublic/myth-busters

[19] G. Winter, "COVID-19 and emergency planning," vol. 25, no. 4, pp. 184-186, 2020.

[20] S. A. Lauer et al., "The incubation period of coronavirus disease 2019 (COVID-19) from publicly reported confirmed cases: estimation and application," 2020. 
Khalida Shaikh (et al.), Awareness regarding Coronavirus pandemic among the population of Sindh, Pakistan: A crosssectional study

[21] A. Shankar et al., "Cancer Care Delivery Challenges Amidst Coronavirus Disease-19 (COVID-19) Outbreak: Specific Precautions for Cancer Patients and Cancer Care Providers to Prevent Spread," vol. 21, no. 3, pp. 569-573, 2020.

[22] R. Ralph et al., "2019-nCoV (Wuhan virus), a novel Coronavirus: human-to-human transmission, travel-related cases, and vaccine readiness," vol. 14, no. 01, pp. 3-17, 2020.

[23] F. Yu, L. Du, D. M. Ojcius, C. Pan, S. J. M. Jiang, and infection, "Measures for diagnosing and treating infections by a novel coronavirus responsible for a pneumonia outbreak originating in Wuhan, China," 2020.

[24] W. Dodds, "Disease Now and Potential Future Pandemics," in The World's Worst Problems: Springer, 2019, pp. 31-44. 